\title{
The Utilization of Educational Robotics in Saudi Schools: Potentials and Barriers from the Perspective of Saudi Teachers
}

\author{
Badr Salman H. Alsoliman ${ }^{1}$ \\ ${ }^{1}$ King Abdulaziz University, Institute of Educational Graduate Studies, Jeddah, Saudi Arabia \\ Correspondence: Badr Salman H. Alsoliman, King Abdulaziz University, Institute of Educational Graduate \\ Studies, Jeddah, Saudi Arabia. E-mail: bsh_alsoliman@yahoo.com
}

Received: May 29, 2018

doi:10.5539/ies.v11n10p105
Accepted: June 30, 2018 Online Published: September 27, 2018

URL: https://doi.org/10.5539/ies.v11n10p105

\begin{abstract}
Objective: The study aims to determine the barriers and potentials of educational robotics in Saudi schools based on the perceptions of Saudi school teachers. Methods: Both qualitative and quantitative research approaches were opted to assess the aim of the study. An open-ended survey has been conducted among the teachers, who use robotics in their teaching practices. Chi-square test was applied to evaluate the significance of participant's opinion and the association between their characteristics and responses to the survey items. Thematic analysis was further used to evaluate the results qualitatively. Results: Lack of knowledge was observed regarding robotics' application in education. Utilizing robots in education has a positive impact on students' education in Saudi schools. Lack of skills, knowledge, teaching strategies, incentives, adequate infrastructure and policies related to the use of robotics were evaluated as some barriers. Conclusion: Saudi government engaged with the ministry of education must put more efforts to promote the use of robotics in Saudi educational system.
\end{abstract}

Keywords: educational technology system, teaching/learning strategies, improving classroom teaching, intelligent tutoring systems, interactive learning environments

\section{Introduction}

The availability of computers in schools that are equipped with the latest software and learning facilities has encouraged teaching approaches to encompass the use of robotics to enhance technology-oriented teaching strategies (Rappaport et al., 2016). Schools around the world have utilized available technological facilities to introduce teaching strategies that employ the use of robotics in their classes. More developed countries have directed teaching approaches in science, technology, engineering, and math classes towards the utilization of robotics emphasizing the importance of STEM trend. The use of robotics is proven effective in teaching and learning concerned with a variety of subjects. The subjects are not limited to computers, engineering, languages, technology, and science as they provide a new modernized approach to combine entertainment, language, problem-solving and engineering. Teachers play a significant role in the development of students, who excel in their educational robotics class. For instance, Atmatzidou et al. (2018) revealed that students, who were provided strong guidance in solving problems regarding their educational robotics activities, attained greater metacognitive (MC) and problem-solving (PS) skills (Atmatzidou et al., 2018).

Education puts forward the use of robotics and its related programming concepts to facilitate effective learning with technology (Kim et al., 2015). In particular, the US, Japan and Europe have applied different approaches to facilitate education by the use of robotics. These approaches varied between the creation of a solution to real-world problems through team works and the competition over developing a robot that is designed for a certain purpose (Litinas \& Alimisis, 2013). However, using robotics in education faces many barriers in many contexts. These barriers vary between the lack of teachers' time and training, the unavailability of robotics materials, and the suitability of learners' ages and financial obstacles. Such barriers must not be considered as the drawback to the application of educational robotics as the success of many educational institutions globally have proven that these barriers can be overcome with careful planning and efficient use of the available resources (Drăgoicea \& Borangiu, 2016). Although, Saudi Arabia is one of the developed countries that emphasises the use of technology to improve educational outcomes, as less attention has been paid to the utilisation of robotics in Saudi schools. Despite of the huge financial and human resource that have been invested in the Saudi educational system and the government calls for educational modernization, the use of robotics has been applied scarcely in its simplest form in Saudi 
schools. Moreover, the use of robotics in education, and in Saudi schools has been barely addressed by Saudi scholars (Al-Zahrani, 2015). The potentials and barriers to the implementation of educational robotics have become a necessity to draw an outline of current and future implications for educational robotics in the Saudi context. This study aimed to shed light on the reasons behind the Saudi teachers' negligence to such an important trend in the educational field. Moreover, to draw attention to the factors that enable a successful utilization of the available resources in preparing Saudi students for the 21's century skills. Following questions have been developed to identify the core aspect of this study:

What is the perspective of teachers towards the foreseen potential of utilizing educational robotics in Saudi schools?

\section{Literature Review}

Reviewing the literature related to the application of robotics in classroom and its relative strategies have assisted to identify the study sample of teachers by targeting teachers who teach subjects where robotics can be advantageous in their classrooms. The study has also helped in recognizing technicality and reasons behind teacher's perspectives.

\subsection{Advantages of Using Robotics in Teaching School's Subjects}

Jaipal and Angeli (2017) have revealed that the use of educational robotics tools promoted the development of computational thinking skills and considered as an instructional technique that can enhance the interest of preservice teachers, who were undergoing training to teach STEM subjects in schools (Jaipal-Jamani \& Angeli, 2017). A recent study conducted by Alshehri and Sharma (2017) suggested that the approach of educational robotics has been implemented by amending different techniques needed along with the additional supercell business logic. It would help teachers, teaching the same subject to bring uniformity.

\subsection{Strategies to Use Robots in Schools}

Identifying teaching strategies associated with teaching using robots inside classrooms could explain why teachers prefer one method and how this method can be beneficial to clarify teachers' perspective on the use of robotics to enhance teaching practices. Therefore, the study addressed six main strategies of applying robotics in schools to enhance students' learning.

One of the main strategies according to Spolaôr and Benitti (2017) is the "Problem-Solving" strategy, which revolves around the creation of a program to solve problems. In robotics, students are asked to program the robot to execute a particular mission. A student, in this case, tries to accomplish the problem by trying their problem-solving techniques until the task has been accomplished. Bers et al. (2014) have indicated that from the teachers' view, this strategy is observed as a two-sided strategy. In the positive side, teachers perceive the use of a physical object to solve a real-life problem, which has the potential to enhance student's cognition. Moreover, the student investigation and their attempt to solve the problem by trying many codes or instructions help them to create better problem-solving strategies, which is a promotion to the students learning skills. On the other side, robot is recognized by teachers as a complicated task as compared to other technologies in education. They expect students to be distracted by the complexity of the languages rather than the problem of interest, which may lead to frustration. According to Eguchi (2016), teachers perceive this strategy as a great tool to provide students with wide career choices. However, they cited the requirement of a pre-knowledge on robotics and higher levels of schooling ages (elementary and secondary schools) for this strategy to be as the only drawback.

A recent study conducted by Hamdan et al. (2017) showed that Nao robot has been evaluating to aid teaching in the workshop sessions of teachers. With the help of this approach, dyslexia students become less reluctant to interact with the robot and become active physically. Similarly, another strategy of using robots in classes is "Collaborative Learning" strategy that involves collaborative problem-solving and giving motivation to school students (Taylor \& Baek, 2017). The study indicated that it involves two teaching strategies including problem-solving and cooperative learning. It is more focused on using the idea of distributed intelligence by joining the knowledge of the group participants in one project (a problem that needs to be solved). The idea is to let students share their knowledge and overcome barriers related to lack of teachers' involvement in the process of solving the problem. In collaborative learning using robotics, students try to solve the problem by collaboration, which involves student assigning missions to other students in the group based on their related experience and knowledge.

Teachers work with the students as leverage and guidance to the process of learning. Teachers prefer this strategy in teaching when they have little knowledge concerned with programming languages as collaboration with students, who provides them with more information regarding the problem. It also helps them to avoid the embarrassment of not being able to answer students' questions. Teachers view this approach as an unfair 
experience for some students, as the enthused students take over the majority of the work and leave the other students behind (Kokosy et al., 2014). Moreover, such strategy is seen by teachers as time-consuming mission to students as it usually has low completion rates.

Inquiry-based learning is essential in educational robotic activities. Achievement of inquiry skills is not easy and requires a long-term study period. Students have to learn the basic of scientific inquiry. Additionally, they also need to get familiar with robots before learning scientific inquiry (Gaudiello \& Zibetti, 2016). The "Inquiry Learning" strategy is indicated by Pedaste et al. (2013) as an approach that has the similar features with previous strategy but tend to have scientific and systematic orientation. Each of these strategies has its strong and weak points. However, such knowledge can provide an insight into how teachers see strategies and what impact could these strategies have on their perception of using robotics as a teaching tool.

\subsection{Barriers to Use Robotics in Schools}

Khanlari (2016) suggested barriers that are related to teachers in school settings. Teacher's fear of losing control is one of the barriers while using robotics. Similarly, lack of required knowledge to build programs is also a reason behind the activation of the robots. Moreover, Kim et al. (2015) indicated that teachers' lack of teaching strategy that can facilitate the use of robotics in teaching schools' subjects is one of the main obstacles that face teachers who are willing to teach with robotics. Teachers tend to use the way that they were taught.

Although, using robotics proved advantageous in teaching school subjects, countless factors in the educational environment can have a negative impact on the use, perception, and practicality of using robotics in schools (for teachers). Therefore, these factors have been highlighted to help understand reasons behind teachers' reluctance to use robotics in schools in Saudi Arabia. According to studies, barriers to using robotics in schools, revolved around four main categories including teachers, students, institutions/schools and robots themselves.

Barriers concerning students using robots in classes varied according to Kucuk and Sisman (2017) between issues related to the subjects, where students are unable to relate the subject in hands with robotics and continue to suggest student's inability to understand teachers' instructions related to parts of the robots. Another issue raised by Fridin and Belokopytov (2014) is student's ages, as younger students tend not to collaborate effectively and are more inclined to play and touch the robot, which may cause the robots to break or feel frustrated if they were not allowed to touch and manipulate parts of the robot. Moreover, barriers such as unfamiliarity and lack of exposure to robots have a significant negative impact on student's ability to learn with robots (Fridin \& Belokopytov, 2014). Organizational barriers play a key role in impeding efforts made to use robotics in education. Gjovik (2013) indicated that barriers related to institutions/schools have been more or less associated with two main problems. First, the organizations' inability to offer an attractive robotic environment, where student and teachers can practice activities related to robotics in a facilitated and well-equipped labs or classrooms. Second, the lack of financial and incorporeal recognition to teachers, who teach with robots. Related to this, countries' general policies and curriculums have a negative influence on the institutions/schools' ability to encourage teaching and learning with robots.

Finally, the barriers relative to robots themselves are recognized by many studies (Burke \& Grosvenor, 2015; Gjovik, 2013; Kradolfer et al., 2014), which hinder the introduction or use of robotics in schools. These barriers included the cost of the robots, and its durability and flexibility and most importantly the applicability of the robot inside classrooms.

In conclusion, barriers that are faced using robotics in schools to facilitate learning are in most respects related to teachers, schools/institutions, students and robots themselves. In this study, these barriers are investigated from the Saudi teachers' viewpoints to highlight barriers that face Saudi teachers in using robots in their classes and draw an outline for proposals to overcome these barriers. It is evaluated to allow more engagement for Saudi teachers in the use of robotics to teach school subjects.

\section{Methodology}

The qualitative and quantitative research designs have been employed to assess objective of the study.

\subsection{Case Study}

The study used an open-ended electronic survey to collect the needed data from the participants. The snowballing technique was employed, where teachers using robotics can share the link to the survey with their colleagues, who use robotics in their teaching.

\subsection{Participants}

The use of this strategy has enabled the study to collect information from 263 teachers, who apply robotics in their 
classes. The survey consisted of 11 items; four of them required a written statement from the participants to give reasons behind their chosen responses.

\subsection{Instruments and Its Validation}

The rationality of the survey was ensured by checking the clarity of the items, the logical flow and the review of the survey items by three experts in the field to assess the validity of its content (face-validity). Moreover, an alternative form of reliability was employed by comparing respondents' answers to the items that reflect the same trend, where answers ought to conform to each other. The survey was piloted on 10 participants to provide information regarding the clarity, time and suggestion to improve the survey items, which also provide a mean for measuring the internal consistency of the survey (Cronbach's alpha $=0.85$ ).

\subsection{Statistical Analysis}

Survey items were analyzed quantitatively using chi-square test (goodness-of-fit) and chi-square test of independence. The survey was open-ended questions (four items), which were designed to prompt the information about the justification of the respondents' answers. A qualitative technique termed as the thematic analysis was employed to analyze the respondents' written statement.

\section{Results}

The results defined the characteristics of the survey participants in percentages based on the frequency of their responses concerning gender, age, school subject, and experience in teaching, school levels, and geographical locations. Moreover, the chi-square test (goodness-of-fit) was performed to determine the significance of the participants' opinions regarding the 11 items of the survey. The chi-square test of independence evaluated the association between the participant's profile and their responses to the survey items.

The frequency distribution showed that the highest proportion (59\%) of the participants were males and ages of the participants ranged between a majority of $43 \%$ between $31-40$ years. The numbers have fallen respectively: $33 \%$ between $41-50$ years, $16 \%$ between $20-30$ years and $8 \%$ between $51-60$ years. Although, frequencies did not show drastic difference amongst the participants in the gender profile. Ages of participants may indicate the age brackets of willingness to use robotics in the country as there is neither official curriculum nor policies that encourage the use of robotics in Saudi Arabia. Surprisingly, results showed that the participants use robotics in other subjects than the listed subjects, which has been based upon the literature. Majority of the participants chosen the item "other subjects" with the frequency of 34\% and Science comes second (21\%), Computer Science (17\%), Math (13), Physics (11) and English (4\%). There has been lack of information regarding the use of robotics in education and suitability of the curriculum to the application of robotics. Moreover, results showed that majority of participants teach in secondary schools (44\%) and have an experience of 11-20 years in teaching (49\%). In this regard, the percentage of school levels and years of experience in teaching have fallen gradually with: $29 \%$ teach in primary schools, $17 \%$ in elementary and $10 \%$ in pre-school level and $23 \%$ of the participants have spent $21-30$ years in teaching, 19\% have spent 6-10 year, and 9\% have spent 1-5 years in school teaching. Finally, frequency distribution showed that most of the participants were from the western area of the country with the frequency of $39 \%, 21 \%$ were from the middle area, $18 \%$ from the eastern area and $15 \%$ were from the northern area of the country. This geographical percentage indicated the influence of snowballing technique that was used to recruit participants. The results of the chi-square test (goodness-of-fit) showed significance in all the participant opinion regarding the 11 items of the survey (Table 1). 
Table 1. Analysis of the survey items

\begin{tabular}{|c|c|c|c|c|c|c|}
\hline Item & Statement & Agree & Disagree & Not sure & Sig. & $\chi^{2}$ \\
\hline 1 & $\begin{array}{l}\text { Teachers' lack of skills in using robots in education is considered a barrier } \\
\text { to use robotics in teaching. }\end{array}$ & $77 \%$ & $12 \%$ & $11 \%$ & $\mathrm{P}=.000$ & 231.56 \\
\hline 2 & $\begin{array}{l}\text { Teachers' lack of teaching strategies related to robotics is considered a } \\
\text { barrier to use robotics in teaching. }\end{array}$ & $75 \%$ & $11 \%$ & $14 \%$ & $\mathrm{P}=.000$ & 204.89 \\
\hline 3 & $\begin{array}{l}\text { Teachers' lack of information regarding robotics in general is considered a } \\
\text { barrier to use robotics in teaching. }\end{array}$ & $76 \%$ & $16 \%$ & $8 \%$ & $\mathrm{P}=.000$ & 213.93 \\
\hline 4 & $\begin{array}{l}\text { Providing financial incentives to teachers will promote the use of robotics } \\
\text { in schools. }\end{array}$ & $74 \%$ & $13 \%$ & $13 \%$ & $\mathrm{P}=.000$ & 193.46 \\
\hline 5 & $\begin{array}{l}\text { Providing moral incentives to teachers will promote the use of robotics in } \\
\text { schools. }\end{array}$ & $76 \%$ & $10 \%$ & $14 \%$ & $\mathrm{P}=.000$ & 220.34 \\
\hline 6 & My students are familiar with using robots. & $8 \%$ & $59 \%$ & $33 \%$ & $\mathrm{P}=.003$ & 100.88 \\
\hline Item & Statement & Yes & No & $\begin{array}{l}\text { I don’t } \\
\text { know }\end{array}$ & Sig. & $\chi^{2}$ \\
\hline 7 & The curriculum supports/facilitate the use of robotics. & $15 \%$ & $46 \%$ & $39 \%$ & $\mathrm{P}=.000$ & 41.39 \\
\hline 8 & My students' age level is suitable to use robotics in teaching them. & $32 \%$ & $10 \%$ & $58 \%$ & $\mathrm{P}=.000$ & 92.22 \\
\hline 9 & The educational policies supports/facilitate the use of robotics. & $21 \%$ & $52 \%$ & $27 \%$ & $\mathrm{P}=.000$ & 41.61 \\
\hline 10 & My school is equipped to support/facilitate the use of robotics. & $9 \%$ & $51 \%$ & $40 \%$ & $\mathrm{P}=.000$ & 75.40 \\
\hline Item & Statement & Damage & Cost & Unfixable & Sig. & $\chi^{2}$ \\
\hline 11 & $\begin{array}{l}\text { The most important problem that I face when using robots in my teaching } \\
\text { is }\end{array}$ & $8 \%$ & $63 \%$ & $29 \%$ & $\mathrm{P}=.000$ & 123.52 \\
\hline
\end{tabular}

Participants' agreement on items $(1,2,3)$ indicated that Saudi teachers lack the necessary skills that enable them to use robots in education and do not have the knowledge to apply teaching strategies that are compatible with the use of robots in their classrooms. These items were observed by teachers as barriers to the application of robotics with their students. Moreover, participant's responses to item $(4,5)$ showed that encouragement in the form of financial and moral support for teachers, who use robotics in their teaching would facilitate the utilization of robotics in Saudi schools. The implication these items was reflected on the participant's responses to item (6) that showed significant disagreement on the familiarity of their students with robotics to identify the deprivation of Saudi students participating in the 21 st century robotics.

Moving to items that required justification of answers, respondents has significantly chosen "NO" to item (7), and 41 commented on the item. Comments were categorized using thematic analyses to 3 themes: The curriculum is mostly about recalling information ( 23 comments), the curriculum is not suitable for robotics ( 12 comments) and the lack of instruction that address the use of robotics (6 comments). Responses to item (8) have confirmed responses to the items $(1,2,3)$ with significant "I Don't Know" selected to indicated that teachers do not have the adequate information to judge the suitability of robotics to their student's ages. Comments on this item have been focused on the lack of student's familiarity with robotics (11 comments) and the relative low-age of their students to use robots (6 comments). Furthermore, responses to item (9) showed that the answer "NO" was significantly chosen to indicate that the educational policies do not encourage the use of robotics which was due to the neglect of robotics technology in the policies (33 comments) and also due to the lack of recognition to users of robotics in the policies (27 comments). In item (10), participants responses demonstrated the unavailability of the required infrastructure and technology related to the use of robotics in Saudi schools by significantly selecting "NO" which can be related to their answers to the previous item as most of their comments centered around the lack of policies that integrate robotics technology in education (44 comments) and the refusals of implementing and supporting the use of robotics financially inside Saudi schools (37comments). On the last item (11), participant's responses revealed that the robots' cost is the biggest barrier that Saudi teachers face. Other barriers may include school subjects and robot's suitability to avoid damages.

\section{Discussion}

The study found that Saudi teachers observe lack of knowledge in general and teaching strategies related to the application of robotics in education, which supported the findings of Khanlari (2016). Consequently, teachers acknowledge the lack of skills that enable them to apply robotics in their subjects as another barrier that is in most respects related to the little information available about robotics. Moreover, the lack of incentives (moral and financial) have also perceived by teachers as one of the obstacles faced by applying robotics in the educational 
field.

The lack of financial support goes beyond the lack of incentives for teachers to the cost of the robots, which was found by the study as an important problem that, when using robotics in their classrooms and indicated by several studies (Burke \& Grosvenor, 2015; Gjovik, 2013; Kradolfer et al., 2014; Park \& Han, 2016). The required infrastructure for the use of robotics in Saudi schools proved inadequate according to teacher's view, which was also supported by Gjovik (2013). Furthermore, the study pinpointed that Saudi teachers do not recognize the student's aptitude and capability to study with robotics referring the lack of information and literature available to Saudi teachers. Accordingly, teachers feel that students are not exposed enough to robots, which might also not allow them to engage effectively in subjects that are taught using robotics. In line with this, Kazakoff et al. (2013) study indicated that using robotics in teaching programming to children has resulted in higher scores as compared to conventional computer-based programming.

The study has put more focus on studying factors that obstruct the use of robotics in teaching the aforementioned school subject. Educational robotics enhances the children's sequencing skills and its related cognitive abilities and teachers working in the educational field should be aware about this so that valuable insights are provided.

\section{Conclusion}

The study has highlighted barriers included: the lack of skills, knowledge, and teaching strategies related to the use of robotics in Saudi schools. Teachers cannot lead the process of implementing robotics in their classrooms taking into account their lack of knowledge and the inadequacy of their classroom environment unless a shift in the Saudi educational policies has occurred. It is worth noting that these findings reflect teachers' perspectives in a country that has designated a huge budget for investing in educational technology and has official vision (2030 vision, 2017). The results have also shown that more efforts were required by Saudi government, engaged with the ministry of education, in utilizing the advantages of using robotics in education. A study has evaluated that educational robotics can enhance topics embodiment and facilitate social interaction in learning contexts (Di Lieto et al., 2017). The stated barriers can be easily reduced with the help of this perspective. Moreover, educational robotics can also lead to more improvement in students' performance (Lammer et al., 2017). It can be achieved by supporting research in the field, encouraging Saudi teachers' initiatives by eliminating barriers related to the lack of knowledge and awareness, existed educational policies, inadequate infrastructure and lack of incentives and training. The limitation of the study is small sample size that is of 263 teachers. Future studies need to recruit more teachers to get appropriate and effective results.

\section{References}

Alshehri, M., \& Sharma, S. K. (2017). Educational Robotics: Comparative Study and Amendments. International Journal of Computer Science and Network Security, 17(8), 182-186.

Al-Zahrani, A. M. (2015). From passive to active: The impact of the flipped classroom through social learning platforms on higher education students' creative thinking. British Journal of Educational Technology, 46(6), 1133-1148. https://doi.org/10.1111/bjet.12353

Atmatzidou, S., Demetriadis, S., \& Nika, P. (2018). How Does the Degree of Guidance Support Students' Metacognitive and Problem-Solving Skills in Educational Robotics? Journal of Science Education and Technology, 27(1), 70-85. https://doi.org/10.1007/s10956-017-9709-x

Bers, M. U., Flannery, L., Kazakoff, E. R., \& Sullivan, A. (2014). Computational thinking and tinkering: Exploration of an early childhood robotics curriculum. Computers \& Education, 72, 145-157. https://doi.org/10.1016/j.compedu.2013.10.020

Burke, C., \& Grosvenor, I. (2015). The School I'd Like: Revisited: Children and Young People's Reflections on an Education for the 21st Century. Routledge. https://doi.org/10.4324/9781315694979

Di Lieto, M. C., Inguaggiato, E., Castro, E., Cecchi, F., Cioni, G., Dell'Omo, M., ... \& Dario, P. (2017). Educational robotics intervention on executive functions in preschool children: A pilot study. Computers in Human Behavior, 71, 16-23. https://doi.org/10.1016/j.chb.2017.01.018

Drăgoicea, M., \& Borangiu, T. (2012). A Service Science Knowledge Environment in the Cloud. IFAC Proceedings Volumes, 45(6), 1702-1707. https://doi.org/10.3182/20120523-3-RO-2023.00438

Eguchi, A. (2016). RoboCupJunior for promoting STEM education, 21st century skills, and technological advancement through robotics competition. Robotics and Autonomous Systems, 75, 692-699. https://doi.org/10.1016/j.robot.2015.05.013

Fridin, M., \& Belokopytov, M. (2014). Acceptance of socially assistive humanoid robot by preschool and 
elementary school teachers. Computers in Human Behavior, 33, 23-31. https://doi.org/10.1016/j.chb.2013.12.016

Gaudiello, I., \& Zibetti, E. (2016). Learning Robotics, with Robotics, by Robotics: Educational Robotics. John Wiley \& Sons. https://doi.org/10.1002/9781119335740

Gjovik, K. P. (2013). Determining factors that serve as barriers to integrative STEM methodology implementation in K-12 schools (Doctoral dissertation, North Dakota State University).

Hamdan, K., Amorri, A., \& Hamdan, F. (2017). Robot Technology Impact on Dyslexic Students' English Learning. World Academy of Science, Engineering and Technology, International Journal of Social, Behavioral, Educational, Economic, Business and Industrial Engineering, 11(7), 1885-1890.

Jaipal-Jamani, K., \& Angeli, C. (2017). Effect of robotics on elementary preservice teachers' self-efficacy, science learning, and computational thinking. Journal of Science Education and Technology, 26(2), 175-192. https://doi.org/10.1007/s10956-016-9663-z

Kennedy, J. R. (2017). The Impact of Robot Tutor Social Behaviour on Children (Doctoral dissertation, University of Plymouth).

Khanlari, A. (2016). Teachers' perceptions of the benefits and the challenges of integrating educational robots into primary/elementary curricula. European Journal of Engineering Education, 41(3), 320-330. https://doi.org/10.1080/03043797.2015.1056106

Kim, C., Kim, D., Yuan, J., Hill, R. B., Doshi, P., \& Thai, C. N. (2015). Robotics to promote elementary education pre-service teachers' STEM engagement, learning, and teaching. Computers \& Education, 91, 14-31. https://doi.org/10.1016/j.compedu.2015.08.005

Kokosy, A., Micea, M. V., \& Saey, P. (2014). A professional project based learning method in mobile robotics. In Frontiers in Education Conference (FIE), 2014 IEEE (pp. 1-7). IEEE. https://doi.org/10.1109/FIE.2014.7044409

Kradolfer, S., Dubois, S., Riedo, F., Mondada, F., \& Fassa, F. (2014, October). A sociological contribution to understanding the use of robots in schools: The thymio robot. In International Conference on Social Robotics (pp. 217-228). Springer International Publishing. https://doi.org/10.1007/978-3-319-11973-1_22

Kucuk, S., \& Sisman, B. (2017). Behavioral patterns of elementary students and teachers in one-to-one robotics instruction. Computers \& Education, 111, 31-43. https://doi.org/10.1016/j.compedu.2017.04.002

Lammer, L., Lepuschitz, W., Kynigos, C., Giuliano, A., \& Girvan, C. (2017). ER4STEM educational robotics for science, technology, engineering and mathematics. In Robotics in Education (pp. 95-101). Springer, Cham. https://doi.org/10.1007/978-3-319-42975-5_9

Litinas, A., \& Alimisis, D. (2013). Planning, implementation and evaluation of lab activities using robotic technology for teaching the phenomenon of motion. In Proceedings of the 3rd Pan-Hellenic Conference "Integration and Use of ICT in Educational Process". Piraeus: HAICTE \& University of Piraeus (in Greek).

Pedaste, M., Mäeots, M., Siiman, L. A., De Jong, T., Van Riesen, S. A., Kamp, E. T., ... \& Tsourlidaki, E. (2015). Phases of inquiry-based learning: Definitions and the inquiry cycle. Educational research review, $14,47-61$. https://doi.org/10.1016/j.edurev.2015.02.003

Rappaport, J. M., Richter, S. B., \& Kennedy, D. T. (2016). A Strategic Perspective on Using Symbolic Transformation in STEM Education: Robotics and Automation. International Journal of Strategic Decision Sciences (IJSDS), 7(1), 39-75. https://doi.org/10.4018/IJSDS.2016010103

Spolaôr, N., \& Benitti, F. B. V. (2017). Robotics applications grounded in learning theories on tertiary education: A systematic review. Computers \& Education, 112, 97-107. https://doi.org/10.1016/j.compedu.2017.05.001

Taylor, K., \& Baek, Y. (2017). Collaborative Robotics, More Than Just Working in Groups. Journal of Educational Computing Research. https://doi.org/10.1177/0735633117731382

\section{Copyrights}

Copyright for this article is retained by the author(s), with first publication rights granted to the journal.

This is an open-access article distributed under the terms and conditions of the Creative Commons Attribution license (http://creativecommons.org/licenses/by/4.0/). 